\title{
Dispositivo estratégico, resistência e relações de poder: um ensaio sobre a identidade do Centro de Educação Matemática (CEM) e seu papel na (E) educação (M)matemática brasileira*
}

\section{Strategic Device, resistance and power relations: an essay on the identity of the Mathematical Education Center (CEM in the Brazilian abbreviation) and its role in the Brazilian Mathematical Education}

\author{
Heloisa da Silva** \\ Antonio Vicente Marafioti Garnica**
}

\begin{abstract}
Resumo: Este artigo apresenta alguns resultados da investigação realizada sobre o Centro de Educação Matemática (CEM), um grupo de educadores matemáticos da cidade de São Paulo atuante principalmente entre os anos de 1984 e 1997. No ensaio, marcado por um exercício de constituir a identidade do CEM a partir de uma leitura foucaultiana, assume-se que o processo de constituição de identidades não se refere ao que o CEM é ou foi, mas a um conjunto de possibilidades de apreendê-lo a partir de estratégias e iniciativas historicamente contextualizadas. Nessa leitura foucaultiana, que traz à cena conceitos como "dispositivo estratégico", "resistências" e "relações de poder", o CEM é visto como constituindo-se ao criar condições para a constituição da moderna Educação Matemática brasileira.
\end{abstract}

Palavras-chave: Educação Matemática. Identidades. Leitura Foucaultiana.

\begin{abstract}
This paper presents some results of the investigation on the Mathematical Education Centre (CEM), a group of mathematics teachers' educators in São Paulo, Brazil, acting mainly between 1984 and 1997. The essay, marked by an effort to constitute the identity of the CEM based on Foucault, assumes that the identity constitution process is not about what CEM is or was, but mainly about a set of possibilities of apprehending it from its historically contextualized strategies and
\end{abstract}

\footnotetext{
* Agradecemos à Marisa R. Bernardes pelas discussões sobre as posições foucaultianas defendidas neste artigo.

** Professora da Universidade Estadual Paulista "Júlio de Mesquita Filho", Campus de Rio Claro. E-mail: <heloisas@rc.unesp.br>

*** Professor da Universidade Estadual Paulista "Júlio de Mesquita Filho", Campus de Bauru e Rio Claro. E-mail: <vgarnica@fc.unesp.br>
} 
initiatives. In this Foucauldian reading, which brings about concepts such as "strategic device", "resistance" and "power relations", the CEM constitution appears while it creates conditions for the constitution of Brazilian modern mathematical education.

Keywords: Mathematical Instruction. Identities. Foucauldian reading.

\section{Introdução: teorizando identidades}

Este trabalho é um dentre quatro exercícios de análise praticados em pesquisa de doutorado (SILVA, 2006), sendo também o quarto ${ }^{1}$ de uma sequência de artigos publicados a partir dessa tese, cujo tema foi o processo de constituição da identidade do Centro de Educação Matemática (CEM), um grupo reconhecidamente atuante em relação à formação de professores de matemática, nas décadas de 1980 e 1990, na grande São Paulo.

Utilizado pela psicanálise e pelos estudos culturais, o conceito de identidade tornou-se, mais notadamente a partir da década de 1980, objeto de interesse das pesquisas sobre formação de professores, mobilizado por questões voltadas a compreender como ocorre o processo de formação da identidade profissional do professor, além de entender qual o efeito da formação inicial e continuada do professor sobre o desenvolvimento de sua identidade profissional, como esse processo formativo "dá forma" e reestrutura a identidade profissional desse professor e, finalmente, quais os aspectos da identidade cultural do professor do final do século XX (e.g. WALSHAW, 2004; SILVA, 2004; PONTE et al., 2002; CARMONA, 1993). O interesse pela identidade do professor, ou pela identidade de sua profissão, está vinculado ao interesse pelas experiências socioculturais (WREN, 2001), julgando-se que estudar a identidade - vista como um amalgamado de elementos provenientes das experiências vividas pelo indivíduo - possibilita tanto uma compreensão dos motivos pelos quais um profissional trabalha da forma como trabalha, quanto uma configuração de situações e fatores que devem e/ou podem participar de sua formação para que atue de tal e tal forma.

Um estudo mais aprofundado sobre a noção de identidade, porém, revela que os elementos que constituem as identidades são caracterizados de maneiras distintas dependendo dos pontos de vista filosófico, histórico, sociológico e cultural considerados. De acordo com Hall (2003), por evocar uma origem que parece habitar um passado histórico, por meio do qual continuam a manter certa correspondência, as identidades vinculam-se à questão dos recursos da história, da linguagem e da cultura. $\mathrm{O}$ autor afirma que as identidades

\footnotetext{
${ }^{1}$ Trata-se dos artigos Silva e Garnica (2009) - Sobre a identidade do Centro de Educação Matemática (CEM): configurações de uma leitura sociológica -; Silva (2010) - Uma Caracterização do Centro de Educação Matemática - CEM - como uma Comunidade de Prática de Formação Continuada de Professores de Matemática; e Silva e Garnica (2011) - Sobre a identidade do Centro de Educação Matemática (CEM): acidentes de uma leitura cartesiana.
} 
[...] surgem da narrativização do eu, mas a natureza necessariamente ficcional desse processo não diminui, de forma alguma, sua eficácia discursiva, material ou política, mesmo que a sensação de pertencimento, ou seja, a "suturação à história" por meio da qual as identidades surgem, esteja, em parte, no imaginário (assim como no simbólico) e, portanto, sempre, em parte, construída na fantasia ou, ao menos, no interior de um campo fantasmático [...] É precisamente porque as identidades são construídas dentro e não fora do discurso que nós precisamos compreendê-las como produzidas em locais históricos e institucionais específicos, no interior de formações e práticas discursivas específicas, por estratégias e iniciativas específicas. (HALL, 2003, p. 109).

Seguindo essa linha, concebemos identidade como processos de produção de significados - ou invenções, vistas como o avesso de "origem", de "expressões do real" -, para atores pessoais, coletivos ou coisas, que se constituem em meio a discursos com base em um atributo cultural; ou, ainda, como um conjunto de atributos culturais inter-relacionados que prevalecem sobre outras fontes de significado.

Partindo desses pressupostos, em Silva (2006) nos preocupamos em realçar, por meio de fragmentos assinalados por análises narrativas sobre a história e a constituição das identidades do CEM, um movimento que caracterizasse os descentramentos do sujeito (HALL, 2000) nas diferentes abordagens do tema da identidade. Para tanto, coletamos depoimentos de dez integrantes do $\mathrm{CEM}^{2}$. O critério para a seleção desse conjunto de depoentes - constituído por membros fundadores e/ou presidentes e/ou coordenadores de projeto e/ou cursistas apostou na possibilidade de obter discursos diferenciados sobre o grupo, dada a diversidade de papéis desempenhados por cada um. A análise desses depoimentos - da qual a leitura foucaultiana aqui apresentada é uma das faces - considera também outras fontes (por exemplo, fontes escritas, como atas de reunião, projetos, legislações, materiais didáticos produzidos pelo grupo, teses e dissertações sobre temas e situações surgidos nas situações de entrevista).

Levando em conta a diversidade de perspectivas teóricas possíveis para o tratamento do tema, suas complexidades, bem como o tempo disponível para a produção do trabalho, consideramos razoável, para analisar o CEM (a partir dos depoimentos e documentos), abarcar três perspectivas que diferem, principalmente, pelo lugar a partir do qual o sujeito é formado no mundo: no seu 'interior' - perspectiva cartesiana -, na mistura do seu 'interior' com o mundo cultural 'exterior' - perspectiva sociológica -, ou pelas formas como é representado e

\footnotetext{
${ }^{2}$ Antonio José Lopes (Bigode), Anna Franchi, Anna Regina Lanner de Moura, Arlete de Jesus Brito, Dione Lucchesi de Carvalho, Dulce Satiko Onaga, Lucília Bechara Sanchez, Manhúcia Perelberg Libermann, Paulo Sérgio de Oliveira Neves e Regina Maria Pavanello.
} 
interpelado no mundo cultural - perspectiva pós-moderna ${ }^{3}$ (advertimos que poderíamos ter teorizado a partir de outras perspectivas, inclusive as advindas do mundo oriental). O que almejamos mostrar no trabalho foi que diferentes perspectivas constituem identidades distintas para o CEM.

A primeira análise (fragmento), focada no ponto de vista cartesiano, caracterizou-se pela crença em um sujeito "denso", formado e centrado em seu "interior" (SILVA; GARNICA, 2011). Já a segunda, que ressalta o ponto de vista sociológico ${ }^{4}$, assinalou um descentramento desse sujeito ao entender sua formação através de processos sociointerativos (SILVA; GARNICA, 2009). Nos dois casos, a produção de significados para a identidade do CEM deu-se por meio de discussões em torno dos sujeitos que compõem esse grupo. No primeiro deles, o grupo representa um conjunto de pessoas com intenções e perfis similares e, no segundo, o grupo constitui-se mediante configurações (internas e externas) que, por sua vez, exprimem-se a partir das interações e situações de interdependência entre seus integrantes, ou entre eles e pessoas e instituições externas ao grupo.

Objetivando assinalar outro tipo de "descentramento", de modo que o processo de constituição da identidade do grupo não se restringisse a focar os seus integrantes (sujeitos), constituímos uma terceira análise em que relacionamos a identidade do CEM ao significado de comunidade de prática, de acordo com os aspectos fundamentais - estabelecidos por Wenger (2001) - de reconhecimento de uma comunidade com essa característica (de prática). (SILVA, 2010). Enquanto a primeira análise sociológica considerou a constituição da identidade do CEM ocorrendo a partir de configurações (pessoais e coletivas) histórica e socialmente contextualizadas, essa terceira análise baseou-se na noção de uma comunidade típica do mundo social (de prática social) em que os processos de aprendizagem e "formação" de identidades - por meio da participação e coisificaşão - dão-se de forma exclusiva.

Mas, se a teorização sobre a constituição da identidade do CEM obtida pela concepção de comunidades de prática afastou-se daquela concepção de identidade desde sempre ai - para utilizarmos a expressão de Veiga-Neto (2005) - advinda da concepção cartesiana de sujeito, ao analisar a complexidade do social partindo da forma situada, Wenger (2001) acaba concebendo, assim como as teorias sociológicas utilizadas na segunda análise, a constituição da identidade pessoal como um processo sociointerativo que inclui um sujeito (denso pelo acúmulo de experiências) que interage com seu meio.

\footnotetext{
${ }^{3}$ No pensamento filosófico pós-moderno, inspirado no pós-estruturalismo (representado por Foucault e Derrida), o sujeito não é o centro da ação social como no ponto de vista sociológico e, sobretudo, cartesiano. Ele não pensa, fala e produz: ele é pensado, falado e produzido. É, portanto, uma ficção (SILVA, 2001).

${ }^{4}$ Nessa análise sociológica nos pautamos, sobretudo, em Elias (1994) e Elias e Scotson (2000).
} 
Deste modo, levando em conta tal observação, não podemos afirmar que, entre a segunda e terceira análises, houve, de fato, um descentramento do sujeito no que tange ao modo como as teorizações realizadas concebem a constituição da identidade, já que ambas se dão na dialética entre o pessoal e o coletivo.

Assim, seguindo a intenção de ressaltar os descentramentos, bem como seus efeitos no interior de nossas análises, decidimos esboçar uma quarta teorização com a finalidade de mostrar ao leitor o que poderia ser uma análise pós-crítica (quando comparada às análises críticas prévias, ou ao menos à crítica da crítica) da constituição da identidade do CEM. Para tanto, realizamos uma análise desse grupo segundo a perspectiva foucaultiana. É esta análise o foco deste artigo.

\section{Uma leitura foucaultiana do CEM}

Atrás das coisas há 'algo inteiramente diferente': não seu segredo essencial e sem data, mas o segredo que elas são sem essência, ou que sua essência foi construída peça por peça a partir de figuras que lhe eram estranhas.

(Michel Foucault)

Nesta análise nos pautamos, sobretudo, nos livros História da Sexualidade (Volume 1) - A vontade de saber (FOUCAULT, 1977), Microfísica do Poder (FOUCAULT, 1999a) e $A$ verdade e as formas jurídicas (FOUCAULT, 1999b). Nestas obras, os conceitos fundamentais envolvidos são os de poder, saber, interdição e resistência.

No História da Sexualidade (Vol. 1), Foucault analisa pontos de resistência na cadeia de relações de poder sob o dispositivo de sexualidade. Aproveitar essa obra e suas diretrizes para estudar a constituição da identidade do CEM implica a possibilidade de analisar os pontos de resistência na cadeia de relações de poder que envolvem esse grupo sob o dispositivo de (E)educação (M)matemática ${ }^{5}$. Assim, o caminho para a análise do processo de constituição da identidade do CEM, sob uma perspectiva foucaultiana, se dá sob a analítica das relações de poder em que seus integrantes se encontraram inseridos.

Mas a palavra "resistência" é um ponto muito delicado da obra de Foucault, já que falar em resistência abre margem para a injunção de um sujeito (aquele que resiste) que o autor nega. Isso porque, para ele, as resistências (no plural) existem na rede de poder. "Portanto, não existe, com respeito ao poder, um

\footnotetext{
${ }^{5}$ Com o uso da expressão (E)educação (M)matemática (com iniciais maiúsculas e minúsculas) queremos ressaltar que tal dispositivo pode ser visto ora como a área Educação Matemática, ora como a prática educação matemática.
} 
lugar da grande Recusa - a alma da revolta, foco de todas as rebeliões, lei pura do revolucionário." (FOUCAULT, 1977, p. 71). Dito de outra maneira, "a resistência ao poder não é a antítese do poder, não é o outro do poder, mas é o outro numa relação de poder - e não de uma relação de poder..." (VEIGA-NETO, p. 151, 2005, grifo nosso).

Desse modo, somente evidenciando os conflitos é possível vislumbrar-se a possibilidade de resistência, pois "lá onde há poder há resistência, e, no entanto (ou melhor, por isto mesmo), esta nunca se encontra em posição de exterioridade em relação ao poder" (FOUCAULT, 1977, p. 91). Para isso, dentre os procedimentos de exclusão devemos considerar, inclusive, aquele que Foucault (2000) afirmou ser o mais familiar, o de interdição. $\mathrm{O}$ autor mostra como um novo discurso pode emergir em um jogo diferencial de interdição. "O direito privilegiado ou exclusivo do sujeito que fala" (FOUCAULT, 2000, p. 9), a negativa do direito de dizer tudo e a impossibilidade de se falar de tudo em qualquer circunstância formam o tripé do jogo de interdições que, ao se cruzarem, se reforçam ou se compensam e formam uma grade complexa que não cessa de se modificar.

Assim, as contingências impõem a necessidade de o poder ser competente e buscar a produção, o acúmulo e a transmissão do saber. Em contrapartida, o saber, ao instrumentar o poder, assegura o exercício de um poder para quem o detém: é o domínio do perito. É a partir destas práticas disciplinares que Foucault (1999a) sugere a busca dos motivos que levam ao aparecimento dos domínios de saber: poder e saber implicam-se mutuamente.

Por isso, segundo o autor, a história deve ser analisada com foco nas lutas, nas estratégias, nas táticas. Assim, talvez, a partir delas, seja possível pensar a (E) educação (M)matemática como um dispositivo estratégico tal como idealizou Foucault.

Devemos levar em conta que a sexualidade em Foucault $(1977$, p. 98$)$ não significou o elemento mais rígido das relações de poder, mas um dos de maior instrumentalidade porque "utilizável no maior número de manobras, podendo servir de ponto de apoio, de articulação às mais variadas estratégias". Em sua análise, tal dispositivo distinguiu, a partir do século XVIII, quatro grandes conjuntos estratégicos -, a histerização do corpo da mulher, a pedagogização do sexo da criança, a socialização das condutas de procriação e a psiquiatrização do prazer perverso - os quais, ao longo do século XIX, esboçaram como objetos privilegiados do saber: a mulher histérica, a criança masturbadora, o casal malthusiano e o adulto perverso, respectivamente (FOUCAULT, 1977, p. 99-100).

Tentaremos, pois, compreender o que algumas relações de poder podem ter significado para os integrantes do CEM que nelas estiveram envolvidos, seja resistindo ou combatendo, seja consentindo, compactuando ou reforçando 
ações, posições, decisões etc. Mas antes de tomarmos a (E)educação (M)matemática como um dispositivo estratégico para a análise dessas relações de poder, devemos ainda compreender sua potencialidade como tal.

Sobre o termo "dispositivo" Foucault (1999a, p. 244) esclarece:

Através deste termo tento demarcar, em primeiro lugar, um conjunto decididamente heterogêneo que engloba discursos, instituições, organizações arquitetônicas, decisões regulamentares, leis, medidas administrativas, enunciados científicos, proposições filosóficas, morais, filantrópicas. Em suma, o dito e o não dito são os elementos do dispositivo. O dispositivo é a rede que se pode estabelecer entre esses elementos.

Acrescenta ainda que, para que a rede que se estabelece entre os elementos heterogêneos de um conjunto se constitua em um dispositivo, é necessário que, em um determinado momento histórico, tenha respondido a uma emergência, ou seja, tenha ocorrido a predominância de um objetivo estratégico.

Sendo assim, ao suspeitarmos da (E)educação (M)matemática como dispositivo estratégico, devemos então questionar: ela respondeu a alguma emergência? Por que se falou de (E)educação (M)matemática e o que se disse? Quais os efeitos de poder induzidos pelo que se dizia? Quais as relações entre esses discursos, esses efeitos de poder e os prazeres nos quais se investiam? Que saber se formava a partir daí? Em suma, trata-se de determinar, em seu funcionamento e em suas razões de ser, o regime de poder-saber-prazer que sustenta o discurso sobre a (E)educação (M)matemática; trata-se de considerar o fato de se falar de (E)educação (M)matemática, quem fala, os lugares e os pontos de vista de que se fala, as instituições que a promovem, que armazenam e difundem o que dela se diz, em suma, o "fato discursivo" global, a "colocação da educação matemática em discurso".

A maioria dos nossos entrevistados, os integrantes do CEM, afirma que antes do final da década de oitenta (e, portanto, antes da fundação da $\operatorname{SBEM}^{6}$ e dos Programas de Pós-Graduação, mais pontualmente) não havia espaço para a Educação Matemática nas universidades.

O CEM, no meu ponto de vista, só chegou ao ponto que chegou porque não existia, antes dessa época, espaço para quem queria estudar e pesquisar na área. [...] Mas isso tem muito a ver com o fato de que na metade dos anos oitenta, você não tinha onde se expressar, não tinha onde pesquisar. Ainda imperava a idéia do "se você não sabe matemática vai ensinar". [...] Desde que eu assumi (eu acho que o termo mais correto é esse) a liderança do grupo, quando acabou o projeto de Geometria, a fala de que o CEM é uma "Instituição de Ensino \& Pesquisa, sem fins lucrativos, que pretende ser um espaço de investigação para

\footnotetext{
${ }^{6}$ SBEM: Sociedade Brasileira de Educação Matemática, fundada em 1987.
} 
professores em serviço que não têm acesso a programas acadêmicos" é constante, recorrente e pública (Depoimento de Antonio José Lopes Bigode. In: SILVA, 2006 , p. 15). Agora, o que eu posso dizer, [...] é que considero todo esse meu trabalho na universidade, de oitenta e quatro a noventa e um, fortemente alimentado e motivado pelo trabalho do CEM. $\mathrm{Na}$ verdade, a universidade só reconheceu, digamos assim, a "Educação Matemática" em oitenta e sete, que foi quando se realizou o primeiro Encontro Nacional de Educação Matemática (I ENEM), após a fundação da Sociedade Brasileira de Educação Matemática (SBEM), cuja reunião de pré-fundação ocorreu no CLAEM, em Guadalajara - México, onde eu também estive presente, além de dez a doze elementos que também estiveram lá representando o Brasil. [...] Esse trabalho do CEM preencheu muitas lacunas que, na época, eram deixadas pela universidade em termos de educação matemática, porque antes de mil novecentos e oitenta e sete, época em que foi fundada a SBEM, eu nunca havia conseguido respaldo na universidade para ter revistas ou outras vias de publicações em Educação Matemática, nunca. Se tenho o Recherches en Didactique des Mathématiques e outras publicações dos anos setenta, oitenta, foi porque fiz estágio na França e assinei a revista e o primeiro contato com o Vergnaud foi em mil novecentos e setenta e sete, durante este estágio. (Depoimento de Anna Franchi. In: SILVA, 2006, p. 68-69).

De acordo com Miguel et al. (2004, p. 5),

No que tange à área de Educação Matemática, no Brasil, no final da década de 80 e início de 90, começava a se formar um círculo vicioso. Por um lado, se seu reconhecimento adviria da divulgação das pesquisas, por outro os espaços próprios a essa divulgação restringiam-se quase que a duas revistas (Bolema e Zetetiké) e aos trabalhos acadêmicos para fins de titulação. Por todo o país era crescente a organização de núcleos de pesquisas em Educação Matemática, nos Programas de Pós Graduação em Educação, além da consolidação dos Programas de Pós Graduação específicos em Educação Matemática, como o da UNESP-Rio Claro e o da PUC-SP. A Sociedade Brasileira de Educação Matemática, SBEM, nessa época, abrigava em seus Encontros - fossem regionais, estaduais ou nacionais - mais resultados de estudos relativos ao ensino de Matemática, do que, propriamente, de pesquisas acadêmicas sobre Educação Matemática. Ao lado disso, ampliava-se o número de doutores na área, muitos com títulos obtidos fora do país.

Observamos, em um primeiro plano, a inexistência de espaço para a Educação Matemática no que diz respeito às questões, práticas e pesquisas dessa e sobre essa área. Nesse sentido, entende-se que questões relativas à Matemática diziam respeito apenas à produção de matemática e não ao ensino e à aprendizagem do professor ou do aluno ou à formação; enquanto a Educação (a área de pesquisa e as instituições vinculadas a ela) preocupava-se com questões que não envolviam especificamente a problemática do ensino e da aprendizagem de matemática - os educadores não discutiam matemática e não legitimavam a competência do matemático para discutir questões do âmbito da educação. 
Mas pode-se considerar, também, que isso apenas significava que se falava em educação matemática, sim, mas de outra maneira; e que eram outras as pessoas que falavam, a partir de outros pontos de vista e para obter outros efeitos. Miguel et al. (2004, p. 2-4) nos contam que

O após guerra representou uma efervescência da Educação Matemática em todo o mundo. Propostas de renovação curricular ganharam visibilidade em vários países da Europa e dos Estados Unidos. Floresce o desenvolvimento curricular. Psicólogos como Jean Piaget, Robert M. Gagné, Jerome Bruner, B.F. Skinner dão a base teórica de aprendizagem de suporte para as propostas. Na Europa, nomes como Georges Papy, Zoltan Dienes e Caleb Gattegno tornaram-se conhecidos em todo o mundo. [...] O número de projetos cresceu de tal maneira que foi necessário criar um centro de referência, surgindo, assim, o International Clearinghouse on Science and Mathematics Curricular Development, em 1963, em Maryland, sob a direção de J. David Lockard. Em 1969, realizou-se em Lyons, França, o Primeiro Congresso Internacional de Educação Matemática [ICME 1].

\section{Mas também afirmam que}

[...] a partir das três grandes revoluções da modernidade, a Revolução Industrial (1767), a Revolução Americana (1776), e a Revolução Francesa (1789), que as preocupações com a educação matemática da juventude começam a tomar corpo. Mas, o passo mais importante no estabelecimento da Educação Matemática como uma disciplina é devido à contribuição do eminente matemático alemão Felix Klein (1849-1925), que publicou, em 1908, um livro seminal, Matemática Elementar de um Ponto de Vista Avançado. Klein defende uma apresentação, nas escolas, mais em bases psicológicas que sistemáticas (MIGUEL et al., 2004, p. 2-4).

Essa preocupação com questões relacionadas (direta ou indiretamente) ao ensino e aprendizagem da matemática - que serviu de escopo para o uso da expressão educação matemática, bem como para, futuramente, a criação da área Educação Matemática - ecoavam em outras instâncias e épocas, mas em graus e segundo significados distintos.

Essas maneiras diferentes de se falar sobre o mesmo dispositivo perpetuam até hoje. A diferença é que atualmente, no Brasil, a Educação Matemática disciplinarizou-se (ou está em acelerado processo de disciplinarização) e, portanto, aquelas pessoas que eram do CEM têm também um lugar cativo na universidade (mesmo não estando nela), para produzir o seu discurso e obter os efeitos que pretendiam. Como afirmam Miguel et al. (2004), a comunidade emergente de educadores matemáticos é 
[...] eclética e heterogeneamente composta por: professores de matemática que não pesquisam suas práticas e que não vêem com bons olhos os pesquisadores acadêmicos em educação matemática; de pesquisadores acadêmicos em Matemática e em Educação que participam da formação desses professores, mas que não gostam muito de fazer isso e, se pudessem, não o fariam; de matemáticos que não pesquisam nem Matemática e nem Educação, mas que formam, a gosto ou a contragosto, professores de matemática; de pesquisadores matemáticos que gostariam de fazer Educação Matemática, mas que se acham impedidos de fazer o que desejariam fazer; de pedagogos e psicólogos, por alguns considerados matematicamente incultos, mas que realizam pesquisas em Educação Matemática; de matemáticos conteudistas de última hora, moralizadores, arrogantes e inflexíveis, que se imaginam salvadores da pátria e legítimos proprietários e defensores do nível e do rigor da Educação Matemática da população; mas também, por professores de matemática, pesquisadores em matemática, pesquisadores em educação matemática e outros profissionais que fazem e acreditam na educação matemática e tentam, de fato, levar a sério o que fazem. (MIGUEL et al., 2004, p. 23).

Isso ainda não significa que não podemos, então, caracterizar a (E)educação (M)matemática como dispositivo estratégico; afinal, está claro, pelo que disseram nossos depoentes, que o próprio Movimento da Matemática Moderna no ensino brasileiro significou uma emergência de objetivos estratégicos políticos e econômicos que redirecionaram o ensino e aprendizagem da matemática no nosso país (SILVA; GARNICA, 2009). A mudança que ocorre é a do polo dominante desse dispositivo. Como lembra Foucault (1999a, p. 13),

[...] a verdade é centrada na forma do discurso científico e nas instituições que o produzem; está submetida a uma constante incitação econômica e política (necessidade de verdade tanto para a produção econômica, quanto para o poder político); é objeto de várias formas, de uma imensa difusão e de um imenso consumo (circula nos aparelhos de educação ou de informação, cuja extensão no corpo social é relativamente grande, não obstante algumas limitações rigorosas); é produzida e transmitida sob o controle, não exclusivo, mas dominante, de alguns aparelhos políticos ou econômicos (universidade, exército, escritura, meios de comunicação).

Um exemplo sobre essa questão dos polos dominantes de produções de verdades ocorre no seguinte recorte:

Paralelamente, no meio dessas discussões com o Gaulin, apareceu o projeto do Banco Mundial do PADCT. Eu me lembro muito bem que teve uma discussão ideológica se a gente ia participar ou não do projeto, porque "era verba do Banco Mundial", "aumentava a dívida do Brasil" e não sei o que... Depois de grandes conversas, a gente chegou à conclusão de que a gente não tinha autoridade ou inserção social [...] para essa verba não vir. Então, se a gente conseguisse um pouco dessa verba a gente poderia trabalhar, ampliar aquelas nossas 
discussões e ver se elas chegavam um pouquinho na sala de aula, porque elas [as verbas] já iam acabar vindo, a gente sabia, para as universidades. [...] A gente achava que a gente dava conta, que iamos ter pernas e, por isso, não nos vinculamos a outra instituição para podermos ser aceitos. Eu até me lembro de ir negociar na USP, no IME, mas eles não estavam interessados. Fui negociar na FUNBEC que tinha sede na cidade universitária. Negociar era tentar que eles recebessem a verba e nos repassassem. Eu me lembro que a FUNBEC topou que fossemos coordenadores do projeto, mas queriam uma verba de administração e, obviamente, a gente não tinha previsto no projeto. Na Faculdade de Educação eu acho que não havia possibilidade, eu não me lembro exatamente o que aconteceu com a Faculdade de Educação, mas no IME foi por aí e na PUC também era o mesmo esquema. Eles não fariam o projeto se eles não estivessem coordenando (Depoimento de Dione Lucchesi de Carvalho. In: SILVA, 2006, p. 107-108).

Em Burigo (1989), por exemplo, encontramos discursos (também em forma de depoimentos) que dão indícios de como alguns matemáticos respondem a determinadas questões que envolvem a educação matemática. Inclusive, o indicativo nesse trabalho é de que o $\mathrm{GEEM}^{7}$ teve fim quando as estratégias discursivas de sustentação desse grupo começaram a diferir/divergir entre seus membros. Quando as professoras do secundário, que faziam parte do grupo, propuseram a discussão de questões pedagógicas por conta da própria situação político-educacional da época - problemas com a "disseminação" da matemática moderna nas escolas, novas discussões e interferências de outros países, a influência do professor Zoltan Dienes - os matemáticos do grupo divergiram de suas ideias.

O GEEM se alimentava dessa discussão [que ocorria no Ginásio Vocacional], mas não assumia essa discussão como sua. [...] Na medida em que isso prometia uma boa matemática, um bom ensino de matemática, o GEEM acolbia. E no começo a gente não discrimina muito as coisas. Então o GEEM acolheu isso muito bem. Mas realmente não era o mesmo discurso. O GEEM, quando isso começou a criar um compromisso com uma pedagogia, o GEEM foi se deslocando. [...] O GEEM comecou a ficar ambiguo (Depoimento de Lucília Bechara Sanches ${ }^{8}$. In: BURIGO, 1989, p. 203).

A separação era de visão de conbecimento mesmo. Porque para o Dienes o rigor era uma coisa a ser construida e que você constrói junto com a classe, usando a linguagem que os caras estão usando e no começo você trabalha com diagramas [...], fórmula é uma coisa que vem lá para a frente. [...] Então esse tipo de coisa que o Dienes se propunha trabalhar em todas as idéias matemáticas, essa coisa de ir construindo, era uma coisa que assustava muito, porque você trabalha com milhões de incorreções (por parte dos alunos). [...] E as outras pessoas

\footnotetext{
${ }^{7}$ Grupo de Estudo do Ensino de Matemática, de São Paulo, um dos precursores do Movimento Matemática Moderna no Brasil e ao qual vários membros do CEM foram filiados.

${ }^{8} \mathrm{Na}$ época do GEEM, Lucília Bechara Sanchez era supervisora na área da matemática do Serviço de Ensino Vocacional da Secretaria de Educação do Estado de São Paulo, dirigente e coautora de publicações do GEEM.
} 
diziam que a matemática é tão complexa, que se você além de tudo permite essas incorreções os alunos vão aprender tudo errado, que o aluno aprende de tanto ouvir. [...] Como se as incorreções fossem um problema de serem ensinadas e não de uma construção que o aluno está faz̧endo. [...] Então tinha dois times do GEEM muito claros (Depoimento de Dione Lucchesi de Carvalho9. In: BURIGO, 1989, p. 203).

Como nos ensina Foucault (1999b, p. 11), se há uma espécie de história interna, "a história da verdade tal qual como se faz na ou a partir da história das ciências", há também uma história externa ou exterior da verdade, pelo menos em sociedades como a nossa, onde existem vários outros lugares em que a verdade se forma e onde um certo número de regras de jogo são determinadas. Segundo o autor, é dessa história externa que vemos nascer certas formas de subjetividade, certos domínios de objeto e certos tipos de saber.

Entendemos que é nesse sentido que os discursos entre os matemáticos e as professoras, ambos membros do GEEM, se diferenciam: o primeiro pautado no que Foucault define como verdade interna, filiando-se o segundo à verdade externa; o primeiro amparado pela instituição (a universidade), o segundo, fora dela.

[...] Lo que necessita um bueno profesor de matemáticas es principalmente, y sobre todo, saber matemáticas y quanto más mejor! Daí a necessidade de, em todos os cursos programados, figurarem matemáticos das Universidades que propiciam aos futuros professores secundários uma boa vivência com a matemática atual. Esta tem sido a fórmula empregada. (SANGIORGI, 1969a, p. 79 apud BURIGO, 1989, p. 111) ${ }^{10}$.

Quando eu dei esse curso [pelo GEEM] disse claramente que eu estava dando esse curso para os professores secundários, para os professores aprenderem mais coisas, e que se isso ia servir para ensinar ou não no secundário, eu realmente não sabia. Mas, quanto mais o professor sabe, melhor professor ele é [...] (Depoimento de João Alésio de Caroli. In: BURIGO, 1989, p. 195, colchetes nosso) $)^{11}$.

Assim, entende-se que justamente por haver diferentes estratégias de discursos acerca da educação matemática (ou do ensino da matemática, como preferiam os matemáticos) é que se criaram pontos de resistência, tanto por parte dos que já estavam na universidade frente aos que não estavam: os primeiros desejavam manter sua posição de poder, quanto o contrário, já que os segundos almejavam mudar de posição.

\footnotetext{
${ }_{9}^{9} \mathrm{Na}$ época do GEEM, Dione Lucchesi de Carvalho era estudante universitária de Matemática, professora secundária e professora em cursos oferecidos pelo GEEM.

${ }^{10} \mathrm{Na}$ época do GEEM, Osvaldo Sangiorgi, matemático, era professor da Faculdade Mackenzie, fundador e presidente do GEEM, professor secundário e autor de livros didáticos para o secundário.

${ }^{11}$ Alésio de Caroli, matemático, era professor da USP e dirigente do GEEM.
} 
Ele [Sangiorgi] como homem de midia estava de olho na USP. A USP o odiava, mas ele sabia que os professores da USP também gostavam do bocado da escola secundária. [...] Ele sabia trazer (as pessoas). Porque a USP fica pixando, mas o saborzinho da massa eles gostam. (Depoimento não identificado. In: BURIGO, 1989, p. 111, colchetes nosso).

O CEM era um outsider, era um grupo que ocupava uns espaços que as grandes instituições não conseguiam ocupar. Eu não sei se hoje isso é possivel. Eu acho que é mais difícil. [...] Hoje está mais institucionalizado, acho que é muito mais difícil existir um grupo, como no passado, como a gente, que ocupou brechas. [...] Do pouco que eu sei tinha, mas a gente competia de igual para igual e éramos vistos como ameaça. [...] Eu me lembro que, nessa época, a gente participou de algumas reuniōes na USP para combinar como que o dinheiro ia ser repassado. Nós éramos tratados assim como os invasores, mas nós éramos muito arrogantes: a gente mostrava que, enquanto um recém-emérito, o professor Pitombo, recebia um dinheiro para trabalhar com cinco professores na elaboração de kits, a gente estava atingindo quatrocentos professores. Então, a gente achava que o nosso trabalho tinha uma escala que os outros não atingiam. A gente metia os peitos mesmo. Sentava, ouvia um monte: "Olha, vocês não são doutores, vocês não têm nem sede". Mas, a gente tinha um capital bumano e uma abrangência que os outros não tinham. Acho que hoje em dia é muito mais difícil ser arrogante assim... [...] [O que nos assegurava era a nossa] Competência técnica e muita coragem. A gente mostrava o que a gente ia fazer com o dinheiro: fazer pesquisa; ter professores selecionados que iam ganhar bolsas, que fariam coisas; trazerpessoas de fora, que estariam ganhando uma hora internacional de assessoria... E a gente trouxe gente bacana, de vários eventos. Aproveitávamos, também, pessoas que estavam aqui no Brasil chamados por outros projetos. (Depoimento de Paulo Sérgio de Oliveira Neves. In: SILVA, 2006, p. 202-205, colchetes nosso).

Esses trechos mostram como a concepção positiva de tecnologia do poder que Foucault propõe faz sentido. Para ele, poder não é "como um sistema geral de dominação exercida por um elemento ou grupo sobre outro e cujos efeitos, por derivações sucessivas, atravessam o corpo social inteiro" (FOUCAULT, 1977, p. 88); "o" poder não "existe" (no sentido definido do artigo e no sentido duro do verbo), o que existem são "práticas ${ }^{12}$ em que ele se manifesta, atua, funciona e se espalha universal e capilarmente" (VEIGA-NETO, 2005, p. 147). As práticas exercidas pelos professores universitários diferiam daquelas do CEM e isso revelava táticas e estratégias distintas de encarar o processo de ensino e aprendizagem da matemática.

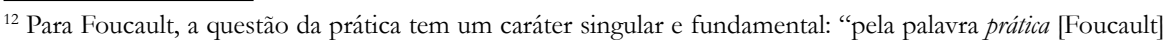
não pretende significar a atividade de um sujeito, [mas] designa a existência objetiva e material de certas regras a que o sujeito está submetido desde o momento em que pratica o "discurso". Os efeitos dessa submissão do sujeito são analisados sob o título: "posições do sujeito"." (LECOURT, 1980, p. 91 apud VEIGA-NETO, p. 54, 2005, grifo do autor). Portanto, é o discurso que constitui a prática.
} 
Usar o dispositivo “(E)educação (M)matemática” ajuda a responder por que aqueles professores precisaram institucionalizar o CEM para trabalhar seus projetos, como também, por que se criou o campo de pesquisa da Educação Matemática, cujos praticantes, inclusive, utilizam o termo "educação matemática" em contraposição a "ensino de matemática", justamente para destacar a distinção entre as formas de concepção de ensino e aprendizagem da matemática envolvidos no discurso por trás de cada expressão.

Ao analisar a Educação Matemática como discurso sob uma perspectiva foucaultiana, Bampi (1999, p. 117) não estudou a Educação Matemática como campo de saber "em seus ideais de progresso, de liberdade, de autonomia e de emancipação"; tampouco perguntou "pelas mudanças instituídas pelo discurso da Matemática - quais são, nem mesmo como serão - nem por que conceptualizá-las como "Educação Matemática" e não como "Ensino de Matemática"”" (BAMPI, 1999, p. 117). Ela colocou a Educação Matemática em seu campo de funcionamento e, tomando-a como discurso, mostrou que "apesar de se inscrever numa matriz crítica, apresenta, [...] efeitos determinados de poder e verdade: sua vontade de totalização e de cidadania plena.” (BAMPI, 1999, p. 117).

Assim, entendemos que nossa tarefa na análise do CEM, nessa leitura, é compreender de que forma os discursos sobre educação matemática se constituíram em período anterior à formação desse grupo para, a partir disso, verificar como esse grupo constituiu-se como ponto de resistência nessa rede de poder.

Analisando a posição das professoras secundárias e dos matemáticos que compunham o GEEM, notamos que as primeiras não somente estavam envolvidas com as escolas secundárias e, portanto, com as práticas ali exercidas, como também se envolveram com discursos amparados em estratégias parecidas e, portanto, condizentes com o contexto institucional em que se encontravam: o contato que tiveram com os colégios vocacionais e experimentais, a escola pública, a formação pedagógica, o contato com os professores Dienes, Vergnaud, Papy e Gaulin, com seus efeitos e posições de poder, reforçaram o discurso daquelas pessoas:

O Professor Papy, no Brasil, foi um conferencista importante no $5^{\circ}$ Congresso Brasileiro de Ensino de Matemática ocorrido em São José dos Campos, em 1966. Ele esteve em vários países da América Latina na década de setenta e circulou, também, nos Estados Unidos, na mesma década. [...] Desde 1971 eu trabalhei no [Colégio] Vera Cruz em cima das idéias do Dienes que, inclusive, veio para o Brasil em setenta e quatro ou setenta e cinco e visitou o Vera Cruz, dando um curso e trabalhando com os alunos que até hoje, como ex-alunos, lembram desta experiência. [...] Ele [Gaulin] foi estrela no sentido de promover a reflexão ao apresentar as várias tendências. Assim, com o GEEM mais enfraquecido, algumas pessoas se aproximaram do Claude e quiseram se organizar porque percebiam as mudanças 
ou porque já não se identificavam com a Matemática Moderna da década de sessenta. (Depoimento de Lucília Bechara Sanchez. In: SILVA, 2006, p. 149-150).

Ainda que estes professores tivessem discursos distintos (às vezes contraditórios), todos colaboravam para uma mesma estratégia, qual seja, a de reforçar o discurso sobre educação matemática por parte daquelas professoras e de todos aqueles que vieram a fazer parte dos grupos Momento (Movimento de Matemáticos por uma Educação Transformadora) ${ }^{13}$ e CEM. É como afirma Walshaw (2004), baseada na reformulação de 'poder' de Foucault:

[...] podemos argumentar que práticas de 'normalização' e 'vigilância' que constroem as relações pedagógicas são produtivas e não podem ser dissociadas do saber. $\mathrm{O}$ argumento de Foucault é que poder e saber se implicam diretamente, mas não são co-extensivos um em relação ao outro: isto é, não pode haver relação de poder sem a correlativa constituição de saber, nem saber que não pressuponha e constitua, simultaneamente, uma relação de poder. (WALSHAW, 2004, p. 67, tradução nossa).

Já os matemáticos do GEEM, estavam, certamente, envolvidos com outras práticas que colaboraram para que assumissem a posição que tinham e, portanto, praticassem o discurso que praticavam:

O conteúdo, nós [do GEEM] estávamos todos chegando no mesmo acordo, que era o conteúdo da matemática moderna. [...] Havia muita diferença (em relação aos métodos). Então, esse professor (Dienes) ele fazia espaço vetorial com os alunos. [...] Era uma obra de arte. Por isso en dizia aos meus colegas: quem vai ser o artista capaz de imitá-lo? (Depoimento de Benedito Castrucci. In: BURIGO, 1989, p. 206) ${ }^{14}$.

Entendemos que esse é um exemplo de como Foucault encara as relações de poder e saber se entrecruzando no sujeito, seu produto concreto, e não num estrato universal abstrato. Por isso uma analítica do sujeito não pode partir do próprio sujeito, mas das camadas que o envolvem e o constituem. O trabalho de Foucault mostra que nos tornamos sujeitos (ou isso a que chamamos de sujeito moderno) "pelos modos de investigação, pelas práticas divisórias e pelos modos de transformação que os outros aplicam e que nós aplicamos sobre nós mesmos" (VEIGA-NETO, 2005, p. 136). Ou, como explica Pinto (1999, p. 39):

Os sujeitos são, irremediavelmente, históricos, trazem em seus corpos a história de sua classe, de seu grupo étnico, de seu gênero. Estas são condições de "estabilidade" do sujeito, de sua concretude, de sua pretensão à totalidade.

\footnotetext{
${ }^{13}$ Cronologicamente, o Momento é um grupo que antecede o CEM, um grupo a partir do qual o CEM é criado.

${ }^{14} \mathrm{Na}$ época do GEEM, Benedito Castrucci, matemático, era professor da Faculdade de Filosofia da USP, dirigente e autor de publicações do GEEM.
} 
A fragmentação não está inscrita neste sujeito, mas na pretensão interpelativa da multiplicidade dos discursos de inclusão e exclusão, que circulam na complexa sociedade contemporânea. Mesmo que essa multiplicidade pareça indicar possibilidades de fragmentação, os discursos, cada um a seu modo, buscam exatamente o contrário, o aprisionamento do sujeito, a sua plena significação.

Assim, na perspectiva de Foucault, sistemas de poder produzem e sustentam os significados que as pessoas fazem delas mesmas e das outras, e é por meio desses sistemas que identidades e subjetividades são estrategicamente formadas e contestadas nas dinâmicas do dia a dia. Portanto, não há que se procurar quem tem o poder na ordem da educação matemática e quem é privado de poder; nem quem tem o direito de saber e quem se mantém na ignorância, mas buscar o esquema das modificações que as correlações de força produzem. As "distribuições de poder" e as "apropriações de saber" não representam mais do que cortes instantâneos em processos, seja de reforço acumulado do elemento mais forte, seja de inversão da relação, seja de aumento simultâneo dos dois termos.

As relações de poder-saber são "matrizes de transformações" (FOUCAULT, 1977, p. 94). O conjunto constituído, nas décadas de 1970 e 1980, por aqueles professores que vieram a formar os grupos Momento e CEM e, provavelmente, por outros grupos fora de São Paulo, seus contatos com professores estrangeiros, além das transformações das leis e diretrizes educacionais, acarretaram modificações no entorno da escola, da educação, e colocaram a educação matemática em questão.

Em uma primeira análise, parece possível distinguir, a partir do final da década de 1970, quatro conjuntos estratégicos a respeito do processo de ensino e aprendizagem da matemática. Eles não surgiram em bloco num determinado momento; mas mostraram certa coerência e atingiram certa eficácia na ordem do poder e produtividade na ordem do saber que nos permitem descrevê-los em sua relativa autonomia: a didatização do professor de matemática - processo pelo qual a qualidade do ensino é colocada em questão e a partir do qual se defende que dominar o conteúdo matemático já não é suficiente para ser um bom profissional; a socialização da aprendizagem da matemática - processo que, por ser contrário à concepção de aprendizagem vista como resultante da "transmissão" de conhecimentos do professor para o aluno, implica colocar o estudante em situações de socialização com vistas a sua aprendizagem; a metodologização do ensino da matemática - processo que, por questionar a qualidade de ensino dada pelo "professor que fala (ensina) e o aluno que escuta (aprende)", implica a busca de formas diversificadas para o ensino da matemática nas quais a participação do aluno é fundamental; a cotidianogização do ensino da matemática - processo pelo qual se busca aproximar o conteúdo matemático do cotidiano das crianças e adolescentes que, 
à época, como resultado das políticas educacionais, começavam a participar de forma massiva do processo de escolarização. Ao longo das décadas seguintes até os dias atuais, podemos dizer que, vinculados a esse conjunto estratégico, configuram-se como objetos privilegiados do saber do educador matemático (pesquisador) alvos e pontos de fixação dos empreendimentos do saber, tanto a formação do professor que ensina matemática quanto a atenção às psicologias e epistemologias da aprendizagem da matemática; bem como a estratégia da resolução de problemas no ensino da matemática, o uso de materiais concretos e jogos para o ensino da matemática; a modelagem matemática e as tecnologias informáticas no ensino da matemática.

Portanto, como enfatizou Bampi (1999), não podemos considerar a existência de um domínio da Educação Matemática que pertence, de direito, a um conhecimento científico, desinteressado e livre (BAMPI, 1999): a Educação Matemática é um campo sobre o qual exigências do poder - econômicas ou ideológicas - fizeram pesar mecanismos de resistência. Parafraseando Foucault (1977), se, por um lado, a educação matemática constituiu-se como domínio a conhecer foi devido a relações de poder que a instituíram como objeto possível e, por outro, se o poder pôde tomá-la como alvo, foi porque se tornou possível vê-la como um conjunto de técnicas de saber e de procedimentos discursivos. $\mathrm{O}$ autor explica que:

Nenhum 'foco local', nenhum 'esquema de transformação' poderia funcionar se, através de uma série de encadeamentos sucessivos, não se inserisse, no final das contas, em uma estratégia global. E, inversamente, nenhuma estratégia poderia proporcionar efeitos globais a não ser apoiada em relações precisas e tênues que lhe servissem, não de aplicação e conseqüência, mas de suporte e ponto de fixação. (FOUCAULT, 1977, p. 95).

Nesse sentido, distinguimos um paralelo entre as relações e as práticas do CEM - como um foco local - e o investimento na pesquisa em educação matemática no Brasil - como estratégia global.

O advento de toda uma série de discursos sobre educação matemática, no pós-guerra, na política e literatura internacionais, permitiu, certamente, um avanço bem marcado dos controles sobre o ensino e aprendizagem da matemática nas escolas (o Movimento da Matemática Moderna representa um foco local desse controle) e, consequentemente, da discussão sobre educação matemática no Brasil; mas também possibilitou a constituição de um discurso "de reação" por parte daqueles que estavam inseridos no ou envolvidos com o contexto institucional escolar e, ao mesmo tempo, tinham, como no caso do CEM, contatos com discursos importados sobre educação matemática que passavam a ser analisados no Brasil. Tal discurso, marcado por pontos de resistência na rede de relações de poder na ordem da Educação Matemática, reivindicava, por sua vez, 
sua legitimidade, muitas vezes, como contam nossos depoentes, seguindo o mesmo ritual acadêmico-científico que o desprestigiava. O depoimento de Lucília Bechara Sanchez é exemplar nesse sentido.

O ataque à Matemática Moderna veio junto com a crítica ao estruturalismo versus funcionalismo, que aconteceu mais ou menos na década de oitenta. Nessa época, no Brasil, começa a ser estudado o pensamento de Vigotsky pelos lingüistas que não viam em Piaget fundamento sufciente para o construtivismo na aprendizagem de lingua. Esta foi, também, uma oportunidade para se construir a crítica ao pensamento de Piaget, ao estruturalismo e à orientação européia que desconsiderava a força do contexto na aprendizagem. O funcionalismo mais pragmático agradou tanto americanos quanto russos que, então, tomavam conta do mundo até o fim da Guerra Fria, em 1989, com a queda do muro de Berlim. Na década de oitenta o GEEM estava mais fraco por questões politicas e por causa do movimento contra a Matemática Moderna e a favor da "Volta ao fundamental" vindo dos Estados Unidos com a bandeira de "Back to Basic". [...] O GEEM tinba toda a possibilidade de fazer a crítica e absorver este novo movimento, já que toda instituicão deve estar aberta para novos movimentos, pois é assim que a bistória se constrói. Entretanto, a Matemática Moderna estava muito ligada à história do GEEM dando assim espaco para outras organizações interessadas em liderar este novo movimento forçarem esta ligacão. Assim sendo, o movimento "Back to Basic" que aconteceu na década de oitenta enfraqueceu o GEEM. [...] Em setenta e nove a Unicamp sediou um Congresso Interamericano de Ensino de Matemática. O Professor Claude Gaulin foi um dos conferencistas mais destacados nesse congresso. Eu já conbecia o Claude Gaulin, pois ele participou do Congresso de Gandia e foi uma das pessoas que me indicon o Dienes. [...] A palestra de Claude Gaulin, que é da Universidade de Laval Québec mostrava um pensamento plural, reflexivo e crítico. O Claude, apesar de ter participado do movimento da Matemática Moderna e trabalhado com o Dienes, apresentou questões teórico-metodológicas muito amplas e discutiu as tendências porque ele conhecia muitos trabalhos em muitos países e participou de quase todos os movimentos desde 1960 sem envolvimento muito intenso. [...] Comesca, então, o trabalho do grupo "Momento" (Movimento de Matemáticos por uma Educacãa Transformadora), liderado, em parte, pelo Claude Gaulin, cuja motivação era refletir e fazer a crítica sobre os movimentos da matemática moderna e o novo movimento para construir novos rumos. (Depoimento de Lucília Bechara Sanches. In: SILVA, 2006, p. 148-149).

Portanto, podemos afirmar que a expressão "educação matemática" foi criada como uma estratégia visando a mudanças de posição de poder nessa rede ordenada pelo dispositivo a que demos o mesmo nome e que, atualmente, como bem pontua Miguel et al. (2004), distingue-se dela por uma zona discursiva caracteristicamente heterogênea que comporta, inclusive, deslocamentos e reutilizações de expressões que nela se legitimam, mas, no entanto, servem para objetivos opostos aos que caracterizaram sua gênese (esta, num sentido genealógico). Como afirma Souza (2005) sobre a caracterização do poder, temos que ter em mente 
[...] que o poder se exerce e que ele não é algo que se conquiste, que se possua, que se perca, que se localize etc, mas algo que todos os sujeitos institucionais exercem e sofrem, em diversas situações e circunstâncias, e no quadro de uma rede de relações de forças assimétricas e móveis. Com mudanças de gestões governamentais mudam também os executivos institucionais do primeiro escalão, alteram-se os quadros funcionais e, conseqüentemente, a redistribuição institucional de exercício de poderes. (SOUZA, 2005, p. 300).

Assim, consideramos que o funcionamento e a história do CEM, sob a analítica das relações de poder, indicam esse grupo como vetor de resistência às estratégias de ensino e aprendizagem da matemática de sua época. Foucault (1977) fala sobre a potencialidade das resistências para a criação de grupos:

As resistências [...] são o outro termo nas relações de poder; inscrevem-se nestas relações como o interlocutor irredutível. Também são, portanto, distribuídas de modo irregular: os pontos, os nós, os focos de resistência disseminam-se com mais ou menos densidade no tempo e no espaço, às vezes provocando o levante de grupos ou indivíduos de maneira definitiva, inflamando certos pontos do corpo, certos momentos da vida, certos tipos de comportamento. (FOUCAULT, 1977, p. 92).

$\mathrm{Na}$ tentativa de analisar questões que dizem respeito a como, a partir de que, por quem e para que as identidades coletivas são construídas, tendo como princípio que tal construção social sempre ocorre em um contexto marcado por relações de poder, Castells (2001) propõe uma distinção entre três formas de identidades que podemos entender como fazendo parte dessa rede de relações de poder sugerida por Foucault: as identidades legitimadora, de resistência e de projeto:

Identidade legitimadora: introduzida pelas instituições dominantes da sociedade no intuito de expandir e racionalizar sua dominação em relação aos atores sociais $[\ldots]$;

Identidade de resistência: criada por atores que se encontram em posições/ condições desvalorizadas e/ou estigmatizadas pela lógica da dominação, construindo, assim, trincheiras de resistência e sobrevivência com base em princípios diferentes dos que permeiam as instituições da sociedade, ou mesmo opostos a estes últimos [...];

Identidade de projeto: quando os atores sociais, utilizando-se de qualquer tipo de material cultural ao seu alcance, constroem uma nova identidade capaz de redefinir sua posição na sociedade e, ao fazê-lo, de buscar a transformação de toda a estrutura social. Esse é o caso, por exemplo, do feminismo que abandona as trincheiras de resistência da identidade e dos direitos da mulher para fazer frente ao patriarcalismo, à família patriarcal e, assim, a toda a estrutura de produção, reprodução, sexualidade e personalidade sobre a qual as sociedades historicamente se estabeleceram. (CASTELLS, 2001, p. 24). 
Do ponto de vista de Castells (2001), cada um desses três processos de construção de identidades pode se converter em outro, caracterizando, assim, uma dinâmica que evidencia o fato de que nenhuma identidade pode constituir uma essência e "nenhuma delas encerra, per se, valor progressista ou retrógrado se estiver fora do seu contexto histórico" (CASTELLS, 2001, p. 24). Além disso, o autor explica que cada um desses processos determina um resultado distinto no que tange à constituição da sociedade: "a identidade legitimadora dá origem a uma sociedade civil", a "identidade destinada à resistência leva à formação de comunas ou comunidades" e a identidade de projetos "produz sujeitos". (CASTELLS, 2001, p. 24-26).

Levando em consideração as proposições desse autor, poderíamos dizer que o grupo CEM, fundado por alguns atores que se encontravam em posições (para eles) desvalorizadas na ordem do dispositivo da (E)educação (M)matemática, construiu trincheiras de resistência que propiciaram a constituição de um coletivo cuja identidade é de resistência. Poderíamos afirmar, além disso, que outros grupos como o CEM propiciaram a formação de uma comunidade, a de pesquisadores em Educação Matemática, que veio se caracterizar, por assim dizer, sob uma identidade de projeto.

O CEM acabou se desfazendo quando não havia mais necessidade de resistir, quando a SBEM e os programas de pós-graduação em Educação Matemática se constituíram e ganharam legitimidade no meio acadêmico-científico, sendo a grande maioria dos seus integrantes incorporados à universidade:

Nessa altura do campeonato, o CEM estava quase partindo para um processo de esvaziamento porque as pessoas estavam encontrando os seus espacos. Foi quando surgiu o Projeto de Resolução de Problemas, e é a partir desse momento que eu começo a bater na tecla de que o CEM é o espaço para aqueles que não têm lugar nas instituições acadêmicas formais. Essa é uma fala minha, nunca contestada, sempre assumida publicamente, e que sempre orientou a nossa ação. Eu sempre fui o cara mais público do CEM, ou seja, sempre assinei CEM, mesmo quando en estava na PUC. Sempre assinei CEM. (Depoimento de Antonio José Lopes Bigode. In: SILVA, 2006, p. 16).

Naquela época, eu acho que a Educação Matemática não tinha se desenvolvido como ela se desenvolveu agora. Eu acho que essa possibilidade (da universidade dever tomar a frente) sempre existiu, a Educação Matemática é que não tinha se desenvolvido tanto. Infeliżmente, ela se desenvolveu numa pesquisa com um formato muito acadêmico. Mesmo a SBEM, eu acho que ela ainda é muito acadêmica. [...] Mas o espaço que a Educação Matemática abriu na Universidade também não é aquele que nós almejávamos no CEM, mas eu acho que deveria estar aqui, na Universidade Pública. Não só as pesquisas deveriam se dedicar mais às questões da sala de aula, mas, também, a interação da Universidade com a Escola Básica Pública deveria ser de outra natureza, de trabalhar mais com projetos envolvendo os professores da Escola Básica e da Universidade. Sei que há algumas iniciativas nesse sentido, mas ainda são muito tímidas e nem sempre valorizadas academicamente (Depoimento de Dione Lucchesi de Carvalho. In: SILVA, 2006, p. 141). 


\section{Concluindo}

Vemos esta nossa teorização não como se ela fosse "uma identidade do CEM segundo Foucault", mas como uma dentre as suas possíveis identidades assumidas por esse grupo. Esse viés analítico, diferentemente dos realizados em outros textos (um movimento analítico cartesiano, um sociológico e um que toma o grupo como uma comunidade de prática), permitiu trazer à baila a (E) educação (M)matemática como dispositivo estratégico e o CEM como um grupo de resistência frente às estratégias educacionais da época em que atuou. Pensamos que Foucault não rechaçaria "essa mascarada" tratada nas análises/fragmentos precedentes, colocando a história em primeiro plano, já que suas metas foram, ao contrário, o uso sacrificial e destruidor da verdade que se opõe à "história-conhecimento". Na verdade, com essa postura, esse autor legitima nossa tese quando afirma que as identidades devem ser dissipadas e que a história não deve apoiar-se em nenhum tipo de continuidade, constância ou plenitude, mas reproduzir o descontínuo e a ruptura que caracterizam nosso próprio ser.

\section{Referências}

BAMPI, L. Efeitos de poder e verdade do discurso da Educação Matemática. Revista Educação e Realidade, Porto Alegre, v. 24, n. 1, p. 115-143, jan./jun. 1999.

BURIGO, E. Z. Movimento da matemática moderna no Brasil: estudo da ação e do pensamento de educadores matemáticos nos anos 80. 1989. 286 f. Dissertação (Mestrado em Educação) - Faculdade de Educação, Universidade Federal do Rio Grande do Sul, Porto Alegre, 1989.

CARMONA, D. R. Identidade profissional dos professores de matemática: processos de formação. 1993. 242 f. Tese (Doutorado em Ciências da Educação) - Faculdade de Ciências e Tecnologia, Universidade Nova, Lisboa, 1993.

CASTELLS, M. A era da informação: economia, sociedade e cultura. São Paulo: Paz e Terra, 2001. (O Poder da Identidade, v. 2).

ELIAS, N. A sociedade dos indivíduos. Organizado por Michael Schröter. Tradução de Vera Ribeiro. Rio de Janeiro: Zahar, 1994.

ELIAS, N.; SCOTSON, J. L. Os estabelecidos e os outsiders: sociologia das relações de poder a partir de uma pequena comunidade. Tradução de Vera Ribeiro. Rio de Janeiro: Zahar, 2000.

FOUCAULT, M. A história da sexualidade I: a vontade de saber. Tradução de Maria Thereza da Costa Albuquerque e José Augusto Guilhon de Albuquerque. Rio de Janeiro: Graal, 1977.

Microfísica do poder. Tradução e organização de Roberto Machado. Rio de Janeiro: Graal, 1999a.

A verdade e as formas jurídicas. Rio de Janeiro: Nau, 1999b. 
A ordem do discurso. Tradução de Laura Fraga de Almeida Sampaio. 6. ed. São Paulo: Loyola, 2000.

HALL, S. A identidade cultural na pós-modernidade. Tradução de Tomaz Tadeu da Silva e Guacira Lopes Louro. Rio de Janeiro: DP \& A, 2000.

Quem precisa da Identidade? In: SILVA, T. T. da (Org.). Identidade e diferença: a perspectiva dos estudos culturais. Petrópolis: Vozes, 2003. p. 103-133.

MIGUEL, A.; GARNICA, A. V. M.; IGLIORI, S. B. C.; D’AMBROSIO, U. A educação matemática: breve histórico, ações implementadas e questões sobre sua disciplinarização. Revista Brasileira de Educação, Campinas, n. 27, p. 70-93, set./dez. 2004. DOI: 10.1590/ S1413-24782004000300006

PINTO, C. R. J. Foucault e as constituições brasileiras: quando a lepra e a peste se encontram com os nossos excluídos. Revista Educação e Realidade, Porto Alegre, v. 24, n. 2, p. 33-57, jul./dez. 1999.

PONTE, P. et al. Development of pré-service mathematics teachers' professional knowledge and identity in working with information and communication technology. Journal of Mathematics Teacher Education, v. 5, n. 2, p. 93-115, 2002.

SILVA, H.; GARNICA, A. V. M. Sobre a identidade do Centro de Educação Matemática (CEM): configurações de uma leitura sociológica. Boletim GEPEM, Rio de Janeiro, v. XXXIII, n. 55, p. 65-92, jul/dez. 2009.

. Sobre a identidade do Centro de Educação Matemática (CEM): acidentes de uma leitura cartesiana. Acta Scientiae, Canoas, v. 13, n. 2, p. 21-38, jul/dez. 2011.

SILVA, H. Centro de Educação Matemática (CEM): fragmentos de identidade. 2006. 448 f. Tese (Doutorado em Educação Matemática) - Instituto de Geociências e Ciências Exatas, UNESP, Rio Claro, 2006.

. Uma Caracterização do Centro de Educação Matemática - CEM (1984-1997) como uma comunidade de prática de formação continuada de professores de matemática. Bolema, Rio Claro, v. 23, n. 35 A, p. 185-218, abr. 2010.

SILVA, S. R. V. Identidade cultural do professor de Matemática a partir de depoimentos (1950-2000). 2004. 259 f. Tese (Doutorado em Educação Matemática) - Instituto de Geociências e Ciências Exatas, UNESP, Rio Claro, 2004.

SOUZA, G. L. D. Educação matemática na CENP: um estudo histórico sobre condições institucionais de produção cultural por parte de uma comunidade de prática. 2005. $432 \mathrm{f}$. Tese (Doutorado em Educação) - Faculdade de Educação, Universidade Estadual de Campinas, Campinas, 2005.

VEIGA-NETO, A. Foucault e a educação. Belo Horizonte: Autêntica, 2005. (Coleção Pensadores \& Educação).

WALSHAW, M. Pré-service mathematics teaching in the context of schools: an exploration into the constitution of identity. Journal of Mathematics Teacher Education, v. 7, n. 1, p. 63-86, 2004. DOI: 10.1023/B:JMTE.0000009972.30248.9c

WENGER, E. Comunidades de práctica: aprendizaje, significado e identidad - cognición e desarrollo humano. Barcelona: Paidós, 2001. 
WREN, T. Cultural identity and personal identity - philosophical reflections on the identity discourse of social psychology. In: MUSSCHUNGA, B. (Ed.). Personal and moral identity. Amsterdam: Kluwer, 2001. p. 231-258.

Recebido em 28/03/2012

Aceito em 28/08/2012 